\title{
MCDM Evaluation of Asset-Based Road Freight Transport Companies Using Key Drivers That Influence the Enterprise Value
}

\author{
Edvardas Liachovičius ${ }^{1}$, Viktor Skrickij ${ }^{2, *}$ and Askoldas Podviezko ${ }^{3}$ (I) \\ 1 Girteka Logistics, Račiu g. 1, LT-03154 Vilnius, Lithuania; Edvardas.Liachovicius@girteka.eu \\ 2 Transport and Logistics Competence Centre, Vilnius Gediminas Technical University, Saulètekio al. 11, \\ LT-10223 Vilnius, Lithuania \\ 3 Faculty of Public Governance and Business, Institute of Business and Economics, \\ Mykolas Romeris University, Ateities g. 20, LT-08303 Vilnius, Lithuania; askoldas@gmail.com \\ * Correspondence: viktor.skrickij@vgtu.lt
}

Received: 9 July 2020; Accepted: 2 September 2020; Published: 4 September 2020

check for updates

\begin{abstract}
Business owners are trying to enhance company value by developing growth strategies. Besides, they need to know what supports and drives the attractiveness to potential investors. Previously to determine company value, only financial drivers were used. These are essential drivers; however, even they do not reflect the overall situation. This paper proposes a novel approach for the solution of the problem of business valuation by taking into account both financial and non-financial drivers and by using several MCDM (multiple criteria decision making) methods simultaneously both for establishing weights and for the evaluation itself. World-leading road freight transport companies were selected for a case study. MCDM methods were used for determining the weights of the drivers and comparing the listed companies. Key drivers were identified, and the ranking of companies is provided.
\end{abstract}

Keywords: value drivers; financial performance; MCDM; business valuation; road freight transport

\section{Introduction}

Currently, road freight transport has the largest market share [1]. In the European Union (EU), $51 \%$ of all the freights are transported by heavy-duty vehicles [2], in the United States of America (USA), this number is even higher and is equal to 63\% [3]. Business owners of these companies are trying to enhance company value by developing growth strategies; they also need to know what supports and drives that value. In this investigation, non-financial key drivers and financial drivers influencing the value of the road freight transport companies are analyzed and the most important are identified. The proposed methodological approach can help organizations to manage their resources by not only improving service quality and increasing level of satisfaction for stakeholders, but also increasing company attractiveness for investors and increasing the sustainability of the business as a whole.

There are three main approaches for the company's value determination [4]: asset-based, income-based, and market-based. Each approach has its application and relevance, depending on the purpose of the valuation. Market-based company valuation is under investigation in this paper.

This paper is organized as follows: In Section 2, the key drivers that other researchers use for company valuation are reviewed, the problem is formulated, and research strategy is presented. In Section 3, the system of drivers for the valuation of the road freight transport company is established, and research methods are described. In Section 4, the weights of most important drivers are defined, 
and analysis of the current situation with the road freight transport companies is provided. In the last section, the discussion is provided.

\section{Literature Review}

Companies' market valuation is based on the expectations of future performance for the investors. Therefore, it is important to define value drivers that investors are using to predict and discriminate the future performance of companies. There are different value drivers, but most of the researchers use only financial ones. Kiss [5] provided an empirical analysis of value drivers in his investigation, eleven of them were taken into account: free cash flow to firm; earnings before interest and taxes (EBIT); tax rate; reinvestment; invested capital; return on invested capital (ROIC); net margin; cost of capital; market return on assets (Market ROA); sales growth rate. It was found that all of them are important. EBIT, reinvestment, invested capital, net margin, and the sales growth rate have a positive effect on a firm's value; however, tax rate and market ROA have a negative impact. Rappaport [6] provided another approach, taking into account managers and investors. Value drivers identified by Rappaport [6] were sales growth rate, operating profit margin, income tax rate, working capital investment, fixed capital investment, the cost of capital, value growth duration-these also are financial drivers. MacDiarmid et al. [4] proposed a methodology for comparison and selection of financial drivers. The eight potential value drivers were analyzed using graphical comparison, followed by the numerical determination of the degree of correlation between the driver and enterprise value (EV) using the Pearson correlation coefficient. Hypothesis testing was finally done to investigate the strength of the relationships between the potential value drivers and EV [4]. The analysis of value drivers performed by Bistrova et al. [7] revealed that the sustainable shareholder value is based on the long-term and stable economic performance, accompanied by the properly implemented corporate governance system, high common reporting standard, rational capital budgeting politics, and high financial results accountability. Considering the factors affecting shareholder wealth, it is possible to increase the investment attractiveness of a company for the existing and potential strategic and retail investors [7]. Śledzik [8] was one, who identified that in value-based management theory, the main focus was all the time on financial value drivers, but currently, there is a serious necessity of intangible valuation resources and identification. The authors used financial and non-financial drivers in the investigation. It was found that most of the existing methods of intellectual capital valuation are difficult to apply, require too much information, or are not completely described [8]. Some of the methods are not numerical; therefore, analysis becomes problematic. The main conclusion is that in the shareholder value creation process, the omission of non-financial drivers by managers would be a serious mistake.

Multiple Criteria Decision Making (MCDM) methods can be implemented for the selection of key value drivers for evaluation of road freight transport companies. MCDM methods are popular for decision-making in a variety of strategic fields, including economics and business. Stojčić et al. [9] provided a systematic review of the application of MCDM for sustainability; it was found that the application of these methods is widely used for decision making in transport and logistics. Sevastjanov and Dymova [10] proposed a new method for stock ranking based on MCDM and optimization. Fuzzy MCDM methods for obtaining the ranking of various alternatives with respect to the order of their preference to a decision-maker were proposed in the literature [11]. Authors used financial drivers in their investigations: the market value of firm to earnings before amortization, interest and tax ratio, ROE, debt to equity ratio, current ratio (current assets to current liabilities), market value to net sales ratio, price to earnings ratio. Drivers used by authors: earnings per share percent change, revenue percent change, change in pretax margin positive, change in return on investment, change in shares outstanding, Earnings per Share (EPS) percent change, depreciation of capital spending, market capitalization, pretax margin, return on investment (ROI), revenue percent change. In their research, Bilbao-Terol et al. [12] developed proposals for constructing portfolios for investors who take into account ethical, social, and environmental criteria when making decisions. Escrig-Olmedo et al. [13] 
continued to develop investment feasibility studies taking into account sustainable investments. In their work, four areas were described: social, environmental, economic, and corporate governance performance. The authors' approach extends the applicability of the solution since the problem is dealt with in a complex way, not just from a financial point of view. Often, scientists select which MCDM method to use intuitively. In [14], authors presented a comprehensive taxonomy to support the application of multiple criteria decision analysis (MCDA). Authors distinguish three main phases: problem formulation, construction of the decision recommendation, and qualitative features and technical support. These phases include a subset of the characteristics that helps the analyst implementing the MCDA process. Such an approach allows to choose the most appropriate methods for the problem under investigation and may be used for automatization of the decision making process.

\section{Problem Formulation and Research Strategy}

After the literature review, it was found that the most important, or key drivers need to be identified and the methodology for company valuation is needed. The main output of this paper performed after surveys, qualitative and quantitative data analysis are the identified key drivers, their weights, and companies' ranking based on financial performance.

For the case study, four asset-based transport companies (X1-X4) based in the USA and two $(X 5, X 6)$ in the EU were used and compared with a Lithuanian company, Girteka Logistics. The biggest company had more than 12,000 trucks, the smallest one more than 3500, and there were 6000 trucks in Girteka Logistics. The capitalization of listed companies is normalized and presented in Figure 1. The period from 2005 January to 2018 December was selected as it enabled reviewing changes in company capitalization pre and post the global financial crisis [15]. As can be seen from Figure 1, during this period, the capitalization of the companies differed significantly. The $\mathrm{X} 2$ company increased in capitalization only by about $3 \%$, while the others $X 1, X 3$, and $X 4$, increased by $60 \%$ over the same period.

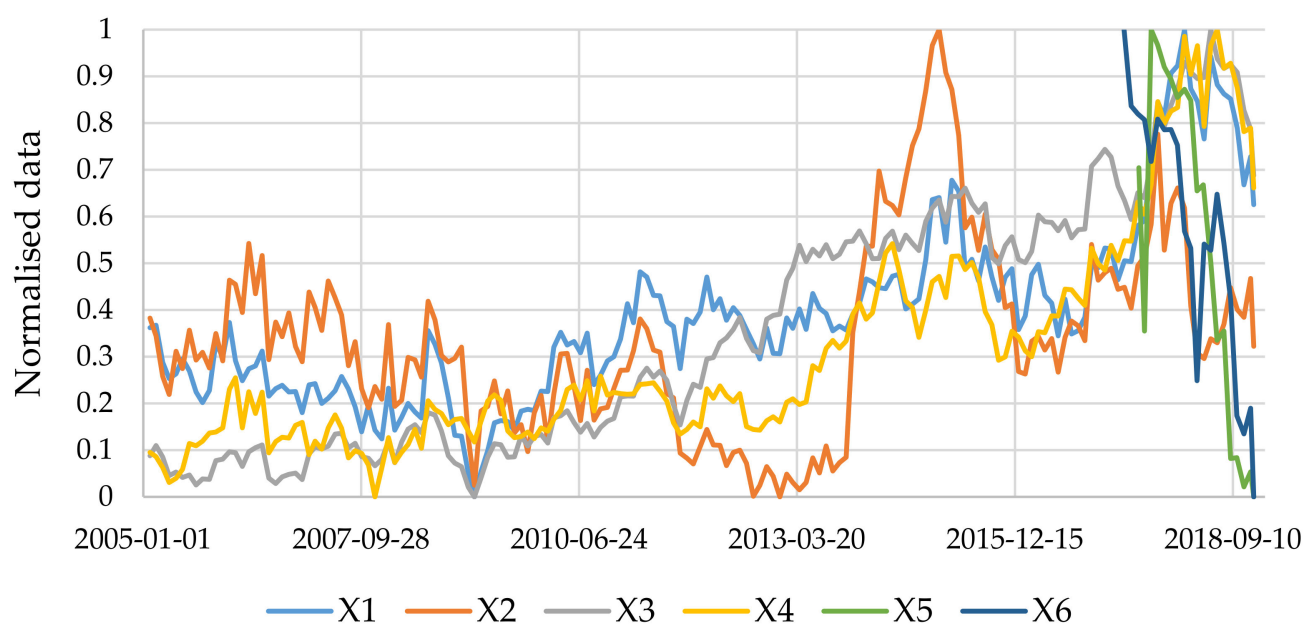

Figure 1. Market capitalization for road freight transport companies during 2005-2018.

Key question-Why companies working in the same field, during the same period, are differently valued by investors? The novelty of the work includes sets of both financial and non-financial drivers that influence the enterprise value. The weights of importance of the identified drivers were estimated; and MCDM evaluation was performed using different methods with a different logic and ways of normalization. Specific steps to reach this goal are presented in Figure 2. 


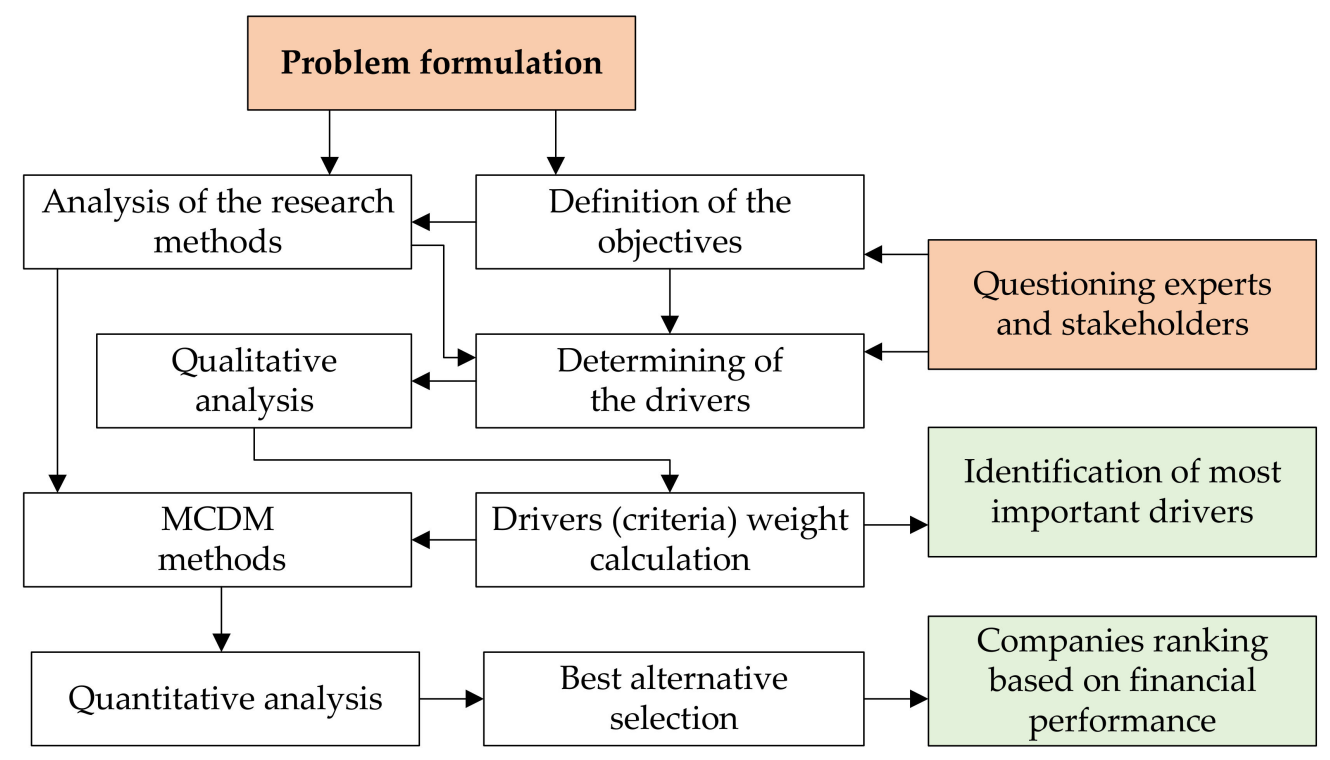

Figure 2. Research strategy.

\section{Research Methods}

In this research, we use the driver term instead of criterion; however, it has the same meaning in the MCDM theory. Two sets of drivers were determined by conducting surveys with experts, stakeholders, and based on literature review. Experts in our case were professional investors, stakeholders-representatives of asset-based transport companies. The set of drivers that influence the choice of investors are presented in Figure 3.

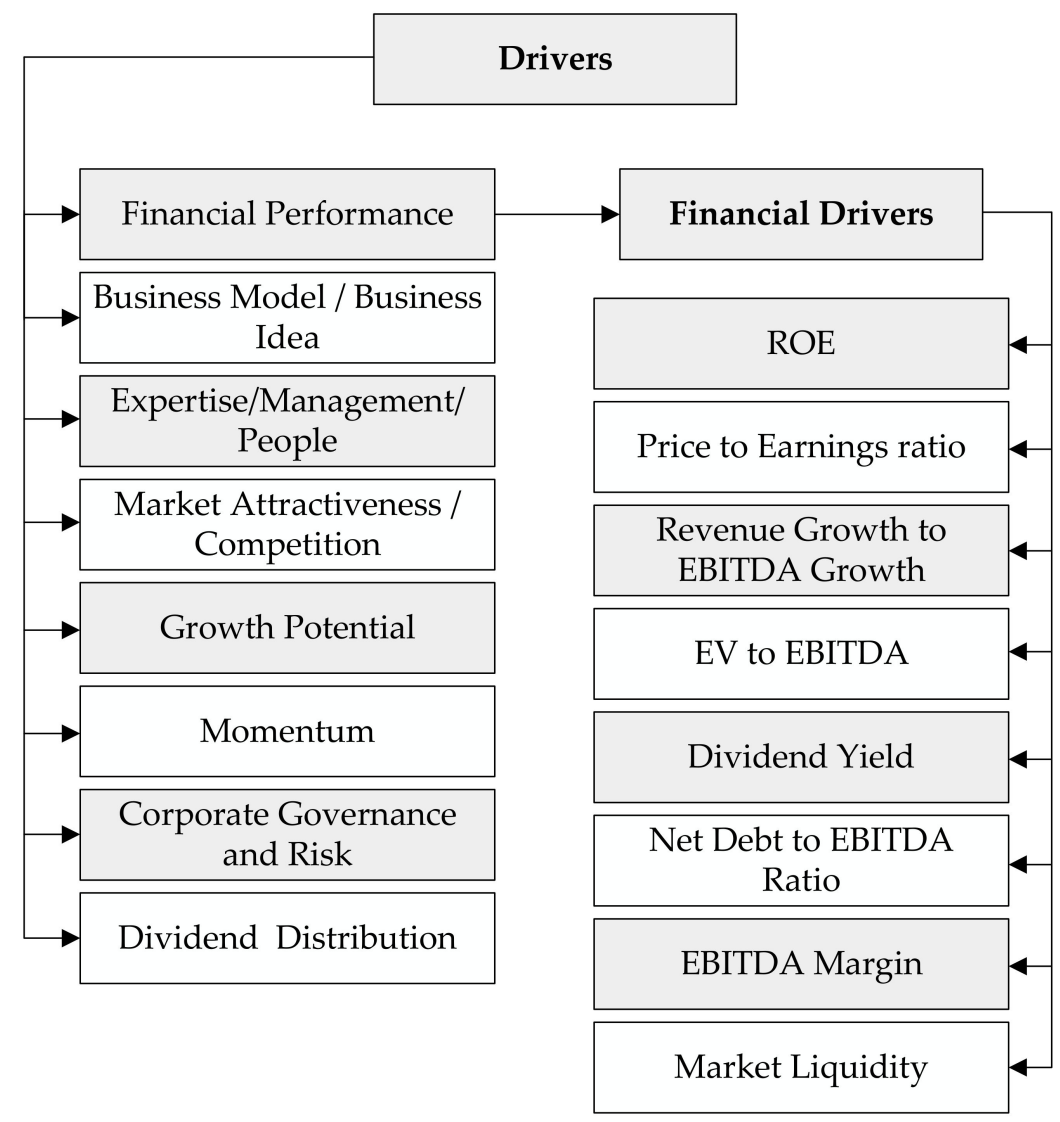

Figure 3. The drivers that influence the enterprise value. 
The general criteria set consists of key drivers that have different qualitative features, some of them can be described using only subjective characteristics. One of the non-financial drivers is the business model (business idea). The second driver is management, taking into account people working in the company and the expertise they have. Market attractiveness, company competition, and its growth potential were defined as an important driver by investors, and need to be taken into account. Some of the investors are looking for momentum, it is the rate of acceleration at which the price is changing. Another driver is corporate governance and the risk is the system of rules, practices, and processes by which a firm is directed and controlled, this driver was taken into account by [13]. Some of the investors are expecting profit not only after the sale of the shares, but want to get dividends, and the company selected strategy has a decisive outcome for investors. The last parameter is the company's financial performance; it is one of the most important drivers. Investments are impossible without analysis of financial situations in the company and most of the researchers are using this kind of driver because numerical values can be identified.

At the next step, the set of financial drivers was set by selecting eight additional drivers that affect the financial performance of a company. They are ROE, revenue growth to earnings before interest, taxes, depreciation, and amortization (EBITDA) growth, enterprise multiple, dividend yield, market liquidity, net debt to EBITDA ratio, EBITDA margin. These drivers can be found in the financial statement (income statement; balance sheet; cash flow statement); all this information is available online from the Bloomberg business platform, as companies under investigation are listed. Information about capitalization and share prices of the companies were taken from the Nasdaq platform—-this information is available online as well.

\subsection{MCDM Evaluation}

In the paper, we used the methods, which reflect a variety of major ideas of the MCDM evaluation: Simple Additive Weeighting (SAW), COmplex PRoportional ASsessment (COPRAS), Technique for Order of Preference by Similarity to Ideal Solution (TOPSIS), Evaluation based on Distance from Average Solution (EDAS), Preference Ranking Organization METHod for Enrichment of Evaluations (PROMETHEE) [16-19]. Several MCDM methods were chosen for this research to increase the reliability of results. Each method has its features and shortcomings while there is no best generally adopted method available yet. Therefore, several methods are often used in the same evaluation; the average evaluation is then usually taken as the ultimate result of the evaluation [20].

The chosen methods discern both by aggregation tools and by types of normalization of values of drivers that are used in each method.

The SAW method uses the commonly used additive weighing full-level aggregation tool [14] that encompasses levels of attractiveness of each alternative expressed by normalized values proportionally to weights of drivers. The COPRAS method even uses the same aggregation tool, has a distinct proprietary normalization that automatically deals with the minimizing drivers without the necessity of transforming them to the maximising ones. Both TOPSIS and EDAS methods use the aggregation tool with the preference model that account for distances to hypothetical best and worst benchmark alternatives. The further is the alternative from the worst benchmark alternative, and the closer it is to the best benchmark alternative, the larger becomes the cumulative criterion of both methods that reflects attractiveness of each evaluated alternative. The PROMETHEE II method uses another distinct preference model that is based on pairwise comparisons of each alternative with all others for obtaining the positive flow, and vice-versa, pairwise comparisons of other alternatives with a chosen one for obtaining the negative flow. The aggregation tool is similar to the one used in the TOPSIS and EDAS methods: the larger is the positive flow, and the smaller is the negative flow, the more attractive the evaluated alternative becomes. In addition, the latter method deals with uncertainty of data with the help of thresholds $q$ and $s$ of the preference function.

Versatility of the chosen methods does not end with variety of aggregation tools used in the paper as, in addition, different types of normalization are involved. Normalization of the minimizing 
drivers in the COPRAS method is proprietary; it considerably differs from the one used in the SAW method. Unlike the normalization used in the previous methods, the TOPSIS method for each driver equalizes the length of vectors with coordinates of alternatives, to the unity length; while the EDAS normalizes weighted sums of positive and negative distances to the corresponding average mid-points. Then, finally, the PROMETHEE II method uses preference functions of a chosen shape and intervals of indifference for mapping the degree of outranking by a certain criterion in each pair of alternatives to the interval $[0,1]$.

The used range of different normalization and aggregation tools employed by the MCDM methods used in the paper should provide a sufficient foundation for testing stability of results by comparing ranks of alternatives obtained by each method.

At the two major stages of MCDM evaluation, estimation of weights and the MCDM evaluation itself, we were dubbing results using methods with different intrinsic logic and normalization [21]. For gauging dynamics of fluctuations of the attractiveness of a specific alternative, the absolute MCDM evaluation could be chosen in addition [18].

For performing the MCDM evaluation along with the alternatives under evaluation, in our case, asset-based road freight transport companies, which we denote as $\mathrm{X} 1, \mathrm{X} 2, \ldots, \mathrm{Xn}$, we need a set vector of weights of all drivers:

$$
\Omega=\left(\omega_{j}\right)
$$

Vector of weights $\Omega$ expresses the relative importance of each driver, where the index $i=1,2, \ldots$, $\mathrm{n}$ denotes alternatives while $j=1,2, \ldots$, m denotes drivers. The decision matrix that contains values of each driver for each alternative is denoted as:

$$
\mathrm{R}=\left\|r_{i j}\right\|
$$

Weights of drivers were estimated in two stages. At the first stage, the drivers were ranked by each expert using the scale of ranks from 1 to $\mathrm{m}$. Rank 1 is assigned to the most important driver; the 2-nd to the second most important; while the rank $\mathrm{m}$ to the least important driver. After completion of the ranking, the statistical criterion of concordance of opinions of the group of experts was used in order to estimate the overall conformity of opinions within the group.

In the second stage, the pairwise comparison method Analytic Hierarchy Process (AHP) was used in order to estimate more exact weights than the ones established by the ranking scale [22,23].

\subsubsection{Estimation of the Level of Concordance of Opinions of Experts}

The model of estimation of the level of concordance of opinions of experts by Kendall [24] uses the coefficient of concordance $W$, which is calculated from the matrix of ranks of drivers $\left.E=\left\|e_{i j}\right\| ; i=1, \ldots m ; j=1, \ldots, r\right), e_{i j}$ are estimation ranks of the $i$-th driver by the $j$-th expert; $\mathrm{m}$ is described earlier; $r$ is the number of experts. The coefficient of concordance $W$ is found involving the following steps [24,25]:

Step 1. The sums $e_{i}=\sum_{j=1}^{r} e_{i j}, i=1, \ldots, m$ of elicited ranks of each driver are calculated;

Step 2. The average of the sums from Step 1 are found: $\bar{e}=\frac{\sum_{i=1}^{m} e_{i}}{m}=\frac{\sum_{i=1}^{m} \sum_{j=1}^{r} e_{i j}}{m}$;

Step 3. The sum of squares of deviations of the sums $e_{i}$ from the average $\bar{e}$, namely $S=\sum_{i=1}^{m}\left(e_{i}-\bar{e}\right)^{2}$, is found;

Step 4. The coefficient of concordance is calculated as follows:

$$
W=\frac{12 S}{r^{2} m\left(m^{2}-1\right)} .
$$

The coefficient of concordance takes values in the interval $(0,1)$, which extreme values mean the following. The value of $W$ close to zero reveals the fact of contradictory opinions among experts while 
$W=1$ or close means that opinions of experts are statistically in line with each other in terms of their cardinal positions of importance estimated by each expert. The following test statistics that use the coefficient of concordance $\mathrm{W}$ serves for testing the hypothesis of concordance of opinions of experts. It was shown [24] that the following test statistics is distributed in accordance with the $\chi^{2}$ distribution with the number of degrees of freedom $v=m-1$ :

$$
\chi^{2}=W r(m-1)=\frac{12 S}{r m(m+1)} .
$$

A level of significance is chosen before testing the hypothesis. In the case, the value of the test statistics appears to be beyond the corresponding to the chosen level of significance critical value $\chi_{k r^{\prime}}^{2}$ the alternative hypothesis $\mathrm{H} 1$ stating that opinions of experts are concordant, may be accepted.

\subsubsection{Estimation of Weights of Drivers Using the AHP Method}

After ranking, weights of drivers were estimated using the AHP method proposed by [22,23]. The essence of the method is pairwise comparisons of the importance of drivers. The resulting matrix of pairwise comparisons $\mathrm{P}=\left\|p_{i j}\right\|,(i, j=1,2, \ldots, m)$ contains ratios of comparison of significance in each pair of drivers $R_{i}$ and $R_{j}(i, j=1,2, \ldots, m)$. The estimation scores $p_{i j}$ are outlined in the scale 1-3-5-7-9 or inverse values. For example, $p_{i j}=1$ means that drivers $R_{i}$ and $R_{j}$ are equally important while $p_{i j}=9$ means that the $i$-th driver is incomparably more important than the $j$-th driver. In the ideal case, the elements of the matrix would contain ratios of weights of drivers:

$$
p_{i j}=\frac{\omega_{i}}{\omega_{j}} .
$$

Nevertheless, despite its shortcomings, the scale makes such comparisons easier for the experts. It is obvious that the matrix $P$ is the inverse symmetrical (reciprocal) matrix, with:

$$
p_{i j}=\frac{1}{p_{j i}},(i, j=1,2, \ldots, m)
$$

It was shown $[22,23]$ that in the case the matrix was filled correctly, the vector of weights $\omega=\left(\omega_{1}, \omega_{2}, \ldots, \omega_{m}\right)^{T}$ could be derived as the normalized eigenvector of the matrix $\mathrm{P}$ that corresponds to the maximal eigenvalue $\lambda_{\max }$ of the matrix $\mathrm{P}$ :

$$
\mathrm{P} \omega=\lambda_{\max } \omega
$$

It was proposed to gauge the consistency of the matrix using the following consistency index (C.I.) $[22,23]$ :

$$
\text { C.I. }=\frac{\lambda_{\max }-m}{m-1} .
$$

In the case when columns of the matrix are strictly proportional, and the matrix is strictly reciprocal, C.I. $=0$. The matrix is considered to be consistent in the case the following concordance ratio (C.R.) is less or equal than 0.1 [22]:

$$
C R=\frac{C . I .}{R . I .}
$$

\subsection{Evaluation and Ranking of Road Freight Transport Companies Using MCDM Methods}

As was explained above, several MCDM methods were chosen for increasing the reliability of results. 


\subsubsection{The SAW Method}

The idea of the MCDM evaluation is implemented in the SAW method in the most evident way. The cumulative criterion of the method $S_{i}$ comprises all normalized (dimensionless) values of drivers for the $i$-th alternative multiplied by their weights:

$$
S_{i}=\sum_{j=1}^{m} \omega_{j} \widetilde{r}_{i j},(i=1,2, \ldots, n),
$$

where $\widetilde{r}_{i j}$ is the normalized (dimensionless) value of the $j$-th driver for the $i$-th alternative.

The SAW method requires both transformation of minimizing drivers into the maximizing ones and normalization, which could be carried out using different formulae [21], for example:

$$
\widetilde{r}_{i j}=\frac{r_{i j}}{\sum_{i=1}^{n} r_{i j}} .
$$

The sum of values of the cumulative criterion $S_{i}$ of all alternatives after such normalization equals to one. A decision-maker may use this feature to derive the exact degree of preference of each alternative relative to others from values of the cumulative criterion as it represents the linear sum of weighted normalized values.

\subsubsection{The COPRAS Method}

We used the COPRAS method both because of its popularity $[26,27]$ and because it accounts for the minimizing drivers in its unique way. The normalization is the same as we used in the SAW method. No additional transformation of the minimizing drivers into the maximizing ones is required. The cumulative criterion of the method $Z_{i}$ is calculated as follows:

$$
Z_{i}=S_{+i}+\frac{\sum_{i=1}^{n} S_{-i}}{S_{-i} \sum_{i=1}^{n} \frac{1}{S_{-i}}},
$$

where $S_{+i}=\sum_{i=1}^{m} \omega_{+j} \widetilde{r}_{+i j}$ is the sum of the weighted normalized values of the maximizing drivers $\widetilde{r}_{+i j}$, while $S_{-i}=\sum_{i=1}^{m} \omega_{-j} \widetilde{r}_{-i j}$ is a similar sum for the minimizing drivers. Since normalization in accordance with formula Equation (11) is used, the sum of values the cumulative criterion for all the alternatives again equals to one as in the SAW method [28].

\subsubsection{The TOPSIS Method}

The major tools of the TOPSIS method are the Euclidean distance in the m-dimensional space:

$$
\widetilde{r}_{i j}=\frac{r_{i j}}{\sqrt{\sum_{i=1}^{n} r_{i j}^{2}}},(i=1, \ldots, n ; j=1, \ldots, m) ;
$$

and vector normalization.

The distance to the best $V^{*}$ and worst alternative $V^{-}$of the alternative in question is measured. Such alternatives $V^{*}$ and $V^{-}$are established artificially by simply taking the best and worst values from the ones placed in the decision matrix, and by multiplying them by corresponding weights:

$$
\begin{aligned}
& V^{*}=\left\{V_{1}^{*}, V_{2}^{*}, \ldots, V_{m}^{*}\right\}=\left\{\left(\max _{i} \omega_{j} \widetilde{r}_{i j} / j \in J_{1}\right), \text { or }\left(\min _{i} \omega_{j} \widetilde{r}_{i j} / j \in J_{2}\right)\right\}, \\
& V^{-}=\left\{V_{1}^{-}, V_{2}^{-}, \ldots, V_{m}^{-}\right\}=\left\{\left(\min _{i} \omega_{j} \widetilde{r}_{i j} / j \in J_{1}\right), \text { or }\left(\max _{i} \omega_{j} \widetilde{r}_{i j} / j \in J_{2}\right)\right\},
\end{aligned}
$$

where $J_{1}$ is the set of indices of the maximizing drivers, while $J_{2}$ is the set of indices of the minimizing drivers. 
Distances $D_{i}^{*}$ and $D_{i}^{-}$of every alternative to the ideal (best) solution and its distance to the worst solution are calculated using the formulae of Euclidean distances:

$$
\begin{aligned}
& D_{i}^{*}=\sqrt{\sum_{j=1}^{m}\left(\omega_{j} \widetilde{r}_{i j}-V_{j}^{*}\right)^{2}}, \\
& D_{i}^{-}=\sqrt{\sum_{j=1}^{m}\left(\omega_{j} \widetilde{r}_{i j}-V_{j}^{-}\right)^{2}} .
\end{aligned}
$$

The cumulative criterion $C_{i}^{*}$ of the method, TOPSIS reflects the position of the $i$-th alternative in terms of its distance from $V^{*}$ and $V^{-}$: the closer it is to the best alternative and the more distant to the worst one, the larger is the cumulative criterion of the TOPSIS method $C_{i}^{*}$ :

$$
C_{i}^{*}=\frac{D_{i}^{-}}{D_{i}^{*}+D_{i}^{-}},(i=1, \ldots, n),\left(0 \leq C_{i}^{*} \leq 1\right) .
$$

The larger is the value of the criterion $C_{i}^{*}$, the better is the alternative and vice versa.

\subsubsection{The EDAS Method}

The EDAS method [29] has similarities with the TOPSIS method described in Section 3.2.3 in terms of gauging distances for constructing the final cumulative score. The EDAS method uses the average solution as a benchmark instead of the best and worst solutions. The positive distance from the average (PD) and a negative distance from the average (ND) are calculated in a few steps.

Step 1. Both decision matrix (formula 1) and the vector of weights (formula 2) are constructed;

Step 2. The average $A V_{j}$ for every driver $\mathrm{j}$ is calculated:

$$
A V_{j}=\sum_{i=1}^{n} \frac{r_{i j}}{n} .
$$

Step 3. Now both positive and negative distances from the average, namely PD and ND, are calculated for the maximizing drivers:

$$
\begin{aligned}
P D_{i j} & =\frac{\max \left(0,\left(r_{i j}-A V_{j}\right)\right)}{A V_{j}}, \\
N D_{i j} & =\frac{\max \left(0,\left(A V_{j}-r_{i j}\right)\right)}{A V_{j}}, \\
P D_{i j} & =\frac{\max \left(0,\left(A V_{j}-r_{i j}\right)\right)}{A V_{j}}, \\
N D_{i j} & =\frac{\max \left(0,\left(r_{i j}-A V_{j}\right)\right)}{A V_{j}},
\end{aligned}
$$

for the minimizing drivers.

Step 4. Weighted sums of PD and ND for each alternative i are found:

$$
\begin{aligned}
& S P_{i}=\sum_{j=1}^{m} w_{j} P D_{i j}, \\
& S N_{i}=\sum_{j=1}^{m} w_{j} N D_{i j} .
\end{aligned}
$$


Step 5. Values SP and SN are normalized for each alternative i:

$$
\begin{aligned}
N S P_{i} & =\frac{S P_{i}}{\max _{i} S P_{i}}, \\
N S N_{i} & =\frac{S N_{i}}{\max _{i} S N_{i}} .
\end{aligned}
$$

Step 6: The cumulative evaluation score (AS) is calculated for each alternative:

$$
A S_{i}=\frac{1}{2}\left(N S P_{i}+N S N_{i}\right), 0 \leq \mathrm{AS}_{\mathrm{i}} \leq 1 .
$$

\subsubsection{The PROMETHEE Method}

The PROMETHEE method is using pairwise comparisons for gauging the differences of the attractiveness of the evaluation of contractors. We recall that the AHP method also belongs to the same realm of methods with the pairwise comparison. The PROMETHEE method uses so-called preference functions $\mathrm{p}(\mathrm{d})$ for normalization, instead of normalized values of drivers $\widetilde{r}_{i j}$ in the SAW and TOPSIS. Differences in values of drivers serve as argument $d$. The shape of preference functions depends on boundary parameters: indifference thresholds $\mathrm{q}$ and $\mathrm{s}$, which are selected by a decision-maker, qualified experts, or using various algorithms available in the literature [30].

The PROMETHEE method compares all the pairs $\mathrm{Xi}$ and $\mathrm{Xk}$ of alternatives by calculating the two aggregated preference (Outranking) indices $\pi\left(\mathrm{Xi}_{\mathrm{i}} \mathrm{Xk}\right)$ of the alternative $\mathrm{Xi}$ in respect of the alternative $\mathrm{Xk}$ and vice versa. The aggregated preference index is calculated using the following formula:

$$
\pi\left(X_{i}, X_{k}\right)=\sum_{j=1}^{m} \omega_{j} p_{t}\left(d_{j}\left(X_{i}, X_{k}\right)\right),
$$

where $d_{j}\left(A_{i}, A_{k}\right)=r_{j i}-r_{j k}$ is the difference between values $r_{j i}$ and $r_{j k}$ of the driver Rj for the alternatives $\mathrm{Xi}$ and $\mathrm{Xk} ; p_{j}=p_{j}\left(d_{j}\left(X_{i}, X_{k}\right)\right)$ is the preference function selected by a decision-maker for the $j$-th driver from the set of different preference functions.

Both positive and negative flows are calculated as follows:

$$
\begin{gathered}
F_{i}^{+}=\sum_{k=1}^{n} \pi\left(X_{i}, X_{k}\right), \\
F_{i}^{-}=\sum_{k=1}^{n} \pi\left(X_{k}, X_{i}\right) .
\end{gathered}
$$

The value of the cumulative criterion of the PROMETHEE II method is calculated as the difference between the positive and negative flows $F_{i}=F_{i}^{+}-F_{i}^{-}$. The rank of the alternative is calculated in accordance with the obtained values of the cumulative criterion, in the decreasing order.

In this paper, the V-shape preference function with indifference was applied, which sensitively reacts to differences $\mathrm{d}$ and nullifies insignificant differences as well as extreme differences.

\section{Results}

\subsection{Gauging Importance of Drivers and Key Drivers}

Eight experts at the initial step were asked to rank all the key drivers and financial drivers in the order of their importance. This step makes it easier to make the pairwise comparison of the importance of drivers required by the AHP method and to assign direct weights as well. The result of such ranking is presented in Tables 1 and 2. 
Table 1. Ranking of key drivers.

\begin{tabular}{lccccccccccc}
\hline & \multirow{2}{*}{ KEY DRIVERS } & \multicolumn{1}{c}{ Expert } & & \multicolumn{3}{c}{ SUM } & Rank \\
\cline { 2 - 11 } & $\mathbf{1}$ & $\mathbf{2}$ & $\mathbf{3}$ & $\mathbf{4}$ & $\mathbf{5}$ & $\mathbf{6}$ & $\mathbf{7}$ & $\mathbf{8}$ & & \\
\hline 1 & Business idea/business model & 3 & 2 & 2 & 1 & 1 & 1 & 1 & 6 & 17 & 1 \\
\hline 2 & Financial performance & 2 & 3 & 6 & 2 & 5 & 3 & 2 & 1 & 24 & 3 \\
\hline 3 & Expertise/management/people & 7 & 1 & 1 & 3 & 3 & 2 & 3 & 2 & 22 & 2 \\
\hline 4 & Market attractiveness/competition & 6 & 4 & 4 & 4 & 2 & 7 & 5 & 3 & 35 & 4 \\
\hline 5 & Growth potential & 5 & 5 & 5 & 6 & 4 & 4 & 4 & 4 & 37 & 5 \\
\hline 6 & Momentum & 8 & 7 & 8 & 8 & 8 & 8 & 6 & 8 & 61 & 8 \\
\hline 7 & Corporate governance and risk & 4 & 6 & 3 & 5 & 6 & 6 & 7 & 5 & 42 & 6 \\
\hline 8 & Dividend distribution & 1 & 8 & 7 & 7 & 7 & 5 & 8 & 7 & 50 & 7 \\
\hline & SUM & 36 & 36 & 36 & 36 & 36 & 36 & 36 & 36 & 288 & 36 \\
\hline
\end{tabular}

Table 2. Ranking of financial drivers.

\begin{tabular}{lccccccccccc}
\hline & \multirow{2}{*}{ DRIVERS } & \multicolumn{1}{c}{ Expert } & & \multicolumn{3}{c}{ SUM } & Rank \\
\cline { 2 - 11 } & & $\mathbf{1}$ & $\mathbf{2}$ & $\mathbf{3}$ & $\mathbf{4}$ & $\mathbf{5}$ & $\mathbf{6}$ & $\mathbf{7}$ & $\mathbf{8}$ & & \\
\hline 1 & Price to earnings ratio & 2 & 2 & 2 & 5 & 1 & 4 & 2 & 7 & 25 & 4 \\
\hline 2 & Return on equity (ROE) & 6 & 3 & 3 & 1 & 2 & 3 & 3 & 1 & 22 & 1 \\
\hline 3 & Revenue growth to EBITDA growth & 1 & 6 & 4 & 2 & 3 & 5 & 1 & 2 & 24 & 3 \\
\hline 4 & Enterprise multiple (EV to EBITDA) & 4 & 1 & 1 & 3 & 6 & 1 & 4 & 3 & 23 & 2 \\
\hline 5 & Dividend yield & 5 & 8 & 8 & 4 & 7 & 2 & 6 & 8 & 48 & 7 \\
\hline 6 & Market liquidity & 8 & 7 & 7 & 6 & 8 & 7 & 8 & 6 & 57 & 8 \\
\hline 7 & Net debt to EBITDA ratio & 3 & 5 & 5 & 7 & 5 & 8 & 5 & 5 & 43 & 5 \\
\hline 8 & EBITDA margin & 7 & 4 & 6 & 8 & 4 & 6 & 7 & 4 & 46 & 6 \\
\hline & SUM & 36 & 36 & 36 & 36 & 36 & 36 & 36 & 36 & 36 & 288 \\
\hline
\end{tabular}

Tables 1 and 2 are matrices of ranks of drivers $\left.E=\left\|e_{i j}\right\| ; i=1, \ldots m ; j=1, \ldots, r\right)$ used in Kendall's theory of concordance. The coefficient of concordance for key drivers appeared to be $\mathrm{W}=0.580$, while for the matrix with financial drivers $\mathrm{W}=0.507$. The $\chi^{2}$ test statistics embedded in the theory of concordance revealed the following results. A priori, we chose the standard level of significance $5 \%$. The number of degrees of freedom in both cases is $v=8-1=7$ as there are eight both sets of drivers. Values of the test statistics appeared to be $\chi^{2}=32.5$ for key drivers and $\chi^{2}=28.417$ for drivers. As the threshold value for the $\chi^{2}$ distribution with 7 degrees of freedom with the chosen level of significance is $\chi_{c r}^{2}=14.067$, we may reject the hypothesis that the opinions of experts in terms of ranks of drivers are non-concordant. Such a case allows the use of elicited weights from the group of experts further in the present research [31].

After the ranking structure of both sets of drivers had been set, they were compared in pairs using the AHP scale. The result of such a comparison by each expert is shown in Tables 3 and 4. 
Table 3. Analytic Hierarchy Process (AHP) comparison matrix for key drivers.

\begin{tabular}{ccccccccc}
\hline & $\mathbf{1}$ & $\mathbf{2}$ & $\mathbf{3}$ & $\mathbf{4}$ & $\mathbf{5}$ & $\mathbf{6}$ & $\mathbf{7}$ & $\mathbf{8}$ \\
\hline 1 & 1 & 3 & 2 & 5 & 5 & 9 & 6 & 7 \\
\hline 2 & $1 / 3$ & 1 & $1 / 2$ & 4 & 4 & 7 & 5 & 6 \\
\hline 3 & $1 / 2$ & 2 & 1 & 4 & 5 & 8 & 5 & 6 \\
\hline 4 & $1 / 5$ & $1 / 4$ & $1 / 4$ & 1 & 2 & 6 & 4 & 5 \\
\hline 5 & $1 / 5$ & $1 / 4$ & $1 / 5$ & $1 / 2$ & 1 & 5 & 4 & 5 \\
\hline 6 & $1 / 9$ & $1 / 7$ & $1 / 8$ & $1 / 6$ & $1 / 5$ & 1 & 2 & 3 \\
\hline 7 & $1 / 6$ & $1 / 5$ & $1 / 5$ & $1 / 4$ & $1 / 4$ & $1 / 2$ & 1 & 2 \\
\hline 8 & $1 / 7$ & $1 / 6$ & $1 / 6$ & $1 / 5$ & $1 / 5$ & $1 / 3$ & $1 / 2$ & 1 \\
\hline
\end{tabular}

Table 4. AHP comparison matrix for the set of financial drivers.

\begin{tabular}{ccccccccc}
\hline & $\mathbf{1}$ & $\mathbf{2}$ & $\mathbf{3}$ & $\mathbf{4}$ & $\mathbf{5}$ & $\mathbf{6}$ & $\mathbf{7}$ & $\mathbf{8}$ \\
\hline 1 & 1 & $1 / 3$ & 1 & 1 & 3 & 5 & 4 & 3 \\
\hline 2 & 3 & 1 & 3 & 2 & 5 & 7 & 6 & 5 \\
\hline 3 & 1 & $1 / 3$ & 1 & 1 & 3 & 4 & 4 & 3 \\
\hline 4 & 1 & $1 / 2$ & 1 & 1 & 4 & 6 & 5 & 4 \\
\hline 5 & $1 / 3$ & $1 / 5$ & $1 / 3$ & $1 / 4$ & 1 & 3 & 2 & 1 \\
\hline 6 & $1 / 5$ & $1 / 7$ & $1 / 4$ & $1 / 6$ & $1 / 3$ & 1 & 1 & 1 \\
\hline 7 & $1 / 4$ & $1 / 6$ & $1 / 4$ & $1 / 5$ & $\frac{1}{2}$ & 1 & 1 & 1 \\
\hline 8 & $1 / 3$ & $1 / 5$ & $1 / 3$ & $1 / 4$ & 1 & 1 & 1 & 1 \\
\hline
\end{tabular}

The above matrices of pairwise evaluation allow estimating weights using the AHP methodology. At the next step, after obtaining the matrices, maximal eigenvalues are to be found for both drivers' sets. For the case of key drivers, we found $\lambda_{\max }=8.83$, while for financial drivers $\lambda_{\max }=8.17$. Both matrices appear to be consistent: for the case of key drivers C.I. $=0.118$ and C.R. $=0.0839$, while for financial drivers C.I. $=0.0247$ and C.R. $=0.0176$. Normalized resulting weights are presented in Table 5 .

Table 5. Overall scoring of value drivers.

\begin{tabular}{ccccccc}
\hline $\mathbf{N r}$ & Key Drivers & Weight & Rank & Financial Drivers & Weight & Rank \\
\hline 1 & $\begin{array}{c}\text { Business model (business } \\
\text { idea) }\end{array}$ & 0.322 & 1 & Price to earnings ratio & 0.1549 & 3 \\
\hline 2 & Financial performance & 0.183 & 3 & $\begin{array}{c}\text { Return on equity } \\
\text { (ROE) }\end{array}$ & 0.3242 & 1 \\
\hline 3 & Expertise/management/people & 0.236 & 2 & $\begin{array}{c}\text { Revenue growth to } \\
\text { EBITDA growth }\end{array}$ & 0.1506 & 4 \\
\hline 4 & $\begin{array}{c}\text { Market attractiveness } \\
\text { (competition) }\end{array}$ & 0.096 & 4 & $\begin{array}{c}\text { Enterprise multiple } \\
\text { (EV to EBITDA) }\end{array}$ & 0.1843 & 2 \\
\hline 5 & Growth potential & 0.077 & 5 & Dividend yield & 0.0623 & $5-6$ \\
\hline 6 & Momentum & 0.032 & 6 & Market liquidity & 0.0355 & 8 \\
\hline 7 & $\begin{array}{c}\text { Corporate governance and } \\
\text { risk }\end{array}$ & 0.031 & 7 & $\begin{array}{c}\text { Net debt to EBITDA } \\
\text { ratio }\end{array}$ & 0.0394 & 7 \\
\hline 8 & Dividend distribution & 0.026 & 8 & EBITDA margin & 0.0488 & $5-6$ \\
\hline
\end{tabular}

Among the key drivers, it was found that the most important ones are business idea; financial performance of the company; expertise, management, and people. While among the financial ones 
(Table 5), the key drivers appear to be: ROE; EV to EBITDA; price to earnings ratio; and revenue growth to EBITDA growth.

\subsection{Case Study: Evaluation of Girteka Logistics}

For the selection of the best alternative, five MCDM methods presented in Section 3.2 were applied. Weights (Table 5) and the decision matrix (Table 6) were used in the evaluation. Values of parameters $\mathrm{q}$ and s listed in Table 7 were used for the PROMETHEE II method. They were elicited from experts.

Table 6. Financial indicators in 2017.

\begin{tabular}{ccccccccccc}
\hline Driver & X3 & X2 & X4 & X1 & X5 & X6 & GIRTEKA & Better & Weight \\
\hline ROE & 0.57 & 0.16 & 0.2 & 0.23 & 0.1 & 0.02 & 0.57 & Max & 0.1549 \\
\hline Price to earnings ratio & 19.7 & 27.11 & 14.31 & 13.87 & 14.46 & 17.9 & $15^{*}$ & Min & 0.3242 \\
\hline Revenue growth to EBITDA growth & 1.04 & 0.89 & 1.02 & 0.99 & 0.94 & 0.99 & 0.9 & Min & 0.1506 \\
\hline Enterprise Multiple (EV to EBITDA) & 11.53 & 12.71 & 7.7 & 7.1 & 6.22 & 13.45 & $6.0^{*}$ & Max & 0.1843 \\
\hline Dividend yield & 0.87 & 0.29 & 0.19 & 0.48 & 0.04 & 0.03 & $0.1^{*}$ & Max & 0.0623 \\
\hline Net debt to EBITDA ratio & 0.88 & 0.05 & 0.18 & 0.15 & 2.41 & 2.22 & 2.1 & Min & 0.0355 \\
\hline EBITDA margin & 14.7 & 23.18 & 19.55 & 16.75 & 12.1 & 7.84 & 20 & Max & 0.0394 \\
\hline Market liquidity & 0.45 & 0.32 & 0.46 & 0.84 & 0.09 & 0.05 & $0.07^{*}$ & Max & 0.0488 \\
\hline
\end{tabular}

Table 7. Values of parameters required in the Preference Ranking Organization METHod for Enrichment of Evaluations (PROMETHEE) method.

\begin{tabular}{ccccccccc}
\hline & $\mathbf{1}$ & $\mathbf{2}$ & $\mathbf{3}$ & $\mathbf{4}$ & $\mathbf{5}$ & $\mathbf{6}$ & $\mathbf{7}$ & $\mathbf{8}$ \\
\hline$q_{j}$ & 0.05 & 0.15 & 0.01 & 0.2 & 0.01 & 0.05 & 0.5 & 0.01 \\
\hline$s_{j}$ & 0.6 & 10 & 0.2 & 8 & 0.9 & 2.4 & 17 & 0.8 \\
\hline
\end{tabular}

For correct application of the methods, it should be taken into account that certain drivers are maximizing, while others are minimizing. All the methods provide results in the form of rankings; the lower rank number represents a better evaluation result for the company. The ranking adheres to the values of the cumulative criteria of each method. The larger is the value, the better rank is assigned. Results of evaluation by all MCDM methods are presented in Table 8, as well as the integral average ranking. Ranks from 1 to 3 were assigned to the same companies by all the methods used. Rank 4 was attained by X4 company using all the four MCDM methods, while only the SAW method yielded rank 5. Achieved results essentially correspond with data presented in Figure 1, the main advantage of the proposed methods is that historical data is not required. The worst situation was for the listed companies registered in the countries of the EU; however, Girteka Logistics attained the average rank three.

After the provided investigation, it can be seen that MCDM allows ranking the companies, and achieved results are consistent with the capitalization of transportation companies (Figure 1). It may be stated that drivers and their weighting were set correctly.

Organizations working if the field of road freight transport may use the most important drivers identified in this research (Figure 4) as key performance indexes. In addition, information about identified drivers could help organizations to manage their resources, increasing company attractiveness for investors. 
Table 8. Companies' ranking using Multiple Criteria Decision Making (MCDM) methods.

\begin{tabular}{cccccccc}
\hline Method & X3 & X2 & X4 & X1 & X5 & X6 & GIRTEKA \\
\hline TOPSIS $C_{i}^{*}$ & 0.7302 & 0.3404 & 0.5250 & 0.5801 & 0.4292 & 0.4079 & 0.6139 \\
\hline Rank & 1 & 7 & 4 & 3 & 5 & 6 & 2 \\
\hline COPRAS $Z_{i}$ & 0.1881 & 0.1302 & 0.1460 & 0.1658 & 0.1079 & 0.1103 & 0.1517 \\
\hline Rank & 1 & 5 & 4 & 2 & 7 & 6 & 3 \\
\hline SAW $S_{i}$ & 0.1825 & 0.1456 & 0.1410 & 0.1614 & 0.1091 & 0.1091 & 0.1512 \\
\hline Rank & 1 & 4 & 5 & 2 & $6-7$ & $6-7$ & 3 \\
\hline PROMETHEE & & & & & & & 1.069 \\
\hline$F_{i}^{+}$ & 1.641 & 1.292 & 1.026 & 1.327 & 0.823 & 1.514 \\
\hline$F_{i}^{-}$ & 1.251 & 2.155 & 0.894 & 0.766 & 1.253 & 1.487 & 0.888 \\
\hline$F_{i}$ & 0.390 & -0.863 & 0.132 & 0.562 & -0.429 & -0.418 & 0.626 \\
\hline Rank & 3 & 7 & 4 & 2 & 6 & 5 & 1 \\
\hline EDAS $A S_{i}$ & 0.908 & 0.281 & 0.494 & 0.679 & 0.097 & 0.111 & 0.539 \\
\hline Rank & 1 & 5 & 4 & 2 & 7 & 6 & 3 \\
\hline Sum of ranks & 7 & 28 & 21 & 11 & 31.5 & 29.5 & 12 \\
\hline Rank & 1 & 5 & 4 & 2 & 7 & 6 & 3 \\
\hline
\end{tabular}

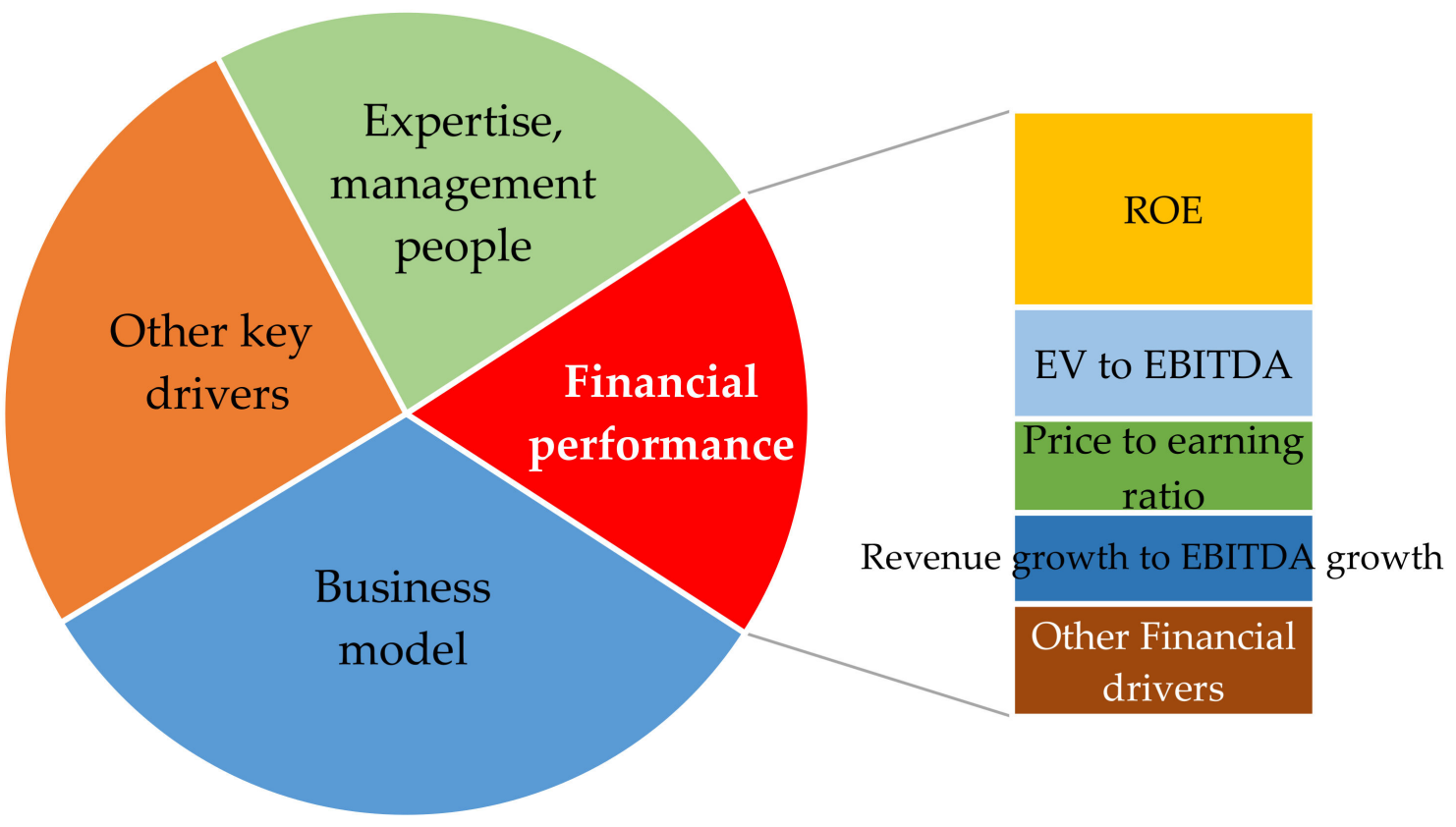

Figure 4. Most important drivers.

Companies' ranking is based on financial data and this analysis does not provide an overview of all the situations. Additional analysis of the companies' business model is needed and the companies' working management people and the expertise they have.

\section{Discussion and Conclusions}

This research investigates key drivers influencing the company value. The developed methodology has been applied for valuation of asset-based road freight transport companies, but can be used in other areas as well. During the literature review, it was found that the authors focus mainly on financial drivers. However, in the value creation process, non-financial drivers play a vital role as well. Specific 
value drivers applicable in the road freight transport industry were identified based on literature review, also, by interviewing experts and stakeholders. Weights of value drivers relevant to road freight transport companies were calculated, and the most important drivers were identified using a novel approach to problem solution implementing the MCDM methods. The AHP method was used for drivers weighting, TOPSIS, COPRAS, SAW, PROMETHEE, EDAS for the best alternative selection.

Top managers working in companies may use key drivers identified in this research for the optimization of internal processes inside the company. In addition, it could help organizations to manage their resources, increasing the sustainability of the company and its attractiveness for investors. The key-drivers identified during this research are business model (weight 0.322), the expertise of the people working in the company and management system (weight 0.236), financial performance (weight 0.183). During further research, four most important financial drivers were identified: price to earnings ratio (weight 0.3242), enterprise multiple (weight 0.1843), ROE (weight 0.1549), revenue growth to EBITDA growth (weight 0.1506). The results obtained during this investigation can be used for a wide range of tasks, from determining key performance indexes to the formulation of the strategic goals of the company.

Problem-solving with MCDM methods allows quantifying the importance of non-financial drivers. As it was shown in this work, different MCDM methods give some scattering of data. Therefore, it is better to use a combination of several methods and use averaged values during decision making.

During the comparison of selected companies, only financial drivers were taken into account. It was found that USA companies are the market leaders, the Lithuanian company Girteka Logistics was ranked in third place and had the highest ranking compared to other European companies. During future research, additional investigation on non-financial drivers is needed.

During the investigation, it was found that investors focus on the company business model. Digitalization is changing the business models over the world. Platforms are becoming more widespread and replace conventional businesses; such examples are Amazon, Uber, Airbnb, and others. The role of the platform is not to develop or manufacture products and services but to connect different sides of a market. In other words, platforms redistribute resources without owning them. Asset-based companies need to find a solution for further development, as companies that will only collaborate with platforms may not be very interesting for investors.

Author Contributions: Conceptualization, E.L., V.S.; Methodology, A.P., V.S.; Investigation, E.L., V.S., A.P.; Writing, E.L., V.S., A.P; Review, A.P. and V.S. All authors have read and agreed to the published version of the manuscript.

Funding: The research received no external funding.

Conflicts of Interest: The authors declare that there is no conflict of interest regarding the publication of this article.

\section{References}

1. Liachovičius, E.; Skrickij, V. The Challenges and Opportunities for Road Freight Transport. In TRANSBALTICA XI: Transportation Science and Technology. TRANSBALTICA 2019. Lecture Notes in Intelligent Transportation and Infrastructure; Gopalakrishnan, K., Prentkovskis, O., Jackiva, I., Junevičius, R., Eds.; Springer: Cham, Germany, 2019. [CrossRef]

2. Research for TRAN Committee-Modal Shift in European Transport: A Way Forward. Policy Department for Structural and Cohesion Policies Directorate-General for Internal Policies PE 629.182 November 2018. Available online: http://www.europarl.europa.eu/RegData/etudes/STUD/2018/629182/IPOL_STU(2018) 629182_EN.pdf (accessed on 1 September 2020).

3. United States Department of Transportation 2017. Bureau of Transportation Statistics. Available online: https://www.bts.gov/newsroom/2017-north-american-freight-numbers (accessed on 1 September 2020).

4. MacDiarmid, J.; Tholana, T.; Musingwini, C. Analysis of key value drivers for major mining companies for the period 2006-2015. Resour. Policy 2018, 56, 16-30. [CrossRef]

5. Kiss, A. Empirical Analysis Of The Role Of The Firms' Value Drivers. Network Intelligence Studies, Fundația Română pentru Inteligența Afacerii. Editor. Dep. 2015, 6, 91-96. 
6. Rappaport, A. Creating Shareholder Value: A Guide for Managers and Investors; Simon and Schuster: New York, NY, USA, 1999; p. 224.

7. Bistrova, J.; Titko, J.; Lace, N. Sustainable Shareholder Value: Analysis of Value Drivers. Econ. Manag. 2014, 19, 129-139. [CrossRef]

8. Śledzik, K. Financial and Non-Financial Value Drivers in Shareholder Value Creation Process. In Young Scientists Revue, Faculty of Management Science and Informatics; Hittmar, S., Ed.; University of Zilina: Žilina, Slovakia, 2013; pp. 89-97. Available online: https://papers.ssrn.com/sol3/papers.cfm?abstract_id=2257767 (accessed on 1 September 2020).

9. Stojčić, M.; Zavadskas, E.K.; Pamučar, D.; Stević, Ž.; Mardani, A. Application of MCDM Methods in Sustainability Engineering: A Literature Review 2008-2018. Symmetry 2019, 11, 350. [CrossRef]

10. Sevastjanov, P.; Dymova, L. Stock screening with use of multiple criteria decision making and optimization. Omega 2009, 37, 259-671. [CrossRef]

11. Mardani, A.; Jusoh, A.; Zavadskas, E.K. Fuzzy multiple criteria decision-making techniques and applications-Two decades review from 1994 to 2014. Expert Syst. Appl. 2015, 42, 4126-4148. [CrossRef]

12. Bilbao-Terol, A.; Arenas-Parra, M.; Cannal-Fernandez, V. A fuzzy multi-objective approach for sustainable investments. Expert Syst. Appl. 2012, 39, 10904-10915. [CrossRef]

13. Escrig-Olmedo, E.; Rivera-Lirio, J.M.; Muñoz-Torres, M.J.; Fernández-Izquierdo, M.A. Integrating multiple ESG investors' preferences into sustainable investment: A fuzzy multicriteria methodological approach. J. Clean. Prod. 2017, 162, 1334-1345. [CrossRef]

14. Cinellia, M.; Kadziński, M.; Gonzalez, M.; Słowiński, R. How to support the application of multiple criteria decision analysis? Let us start with a comprehensive taxonomy. Omega 2020, 96, 102261. [CrossRef]

15. The Global Financial Crisis. Reserve Bank of Australia; 2019. Available online: https://www.rba.gov. au/education/resources/explainers/pdf/the-global-financial-crisis.pdf?v=2019-05-13-16-05-58 (accessed on 1 September 2020).

16. Hwang, C.L.; Yoon, K. Multiple Attribute Decision Making Methods and Applications; Springer: Berlin/Heidelberg, Germany, 1981; p. 335.

17. Brans, J.P.; Mareschal, B. PROMETHEE methods. In Multiple Criteria Decision Analysis: State of the Art 'Surveys'; Figueira, J., Greco, S., Ehrgott, M., Eds.; Springer: New York, NY, USA, 2005; pp. 163-195.

18. Ginevicius, R.; Podvezko, V.; Podviezko, A. Evaluation of Isolated Socio-Economical Processes by a Multi-Criteria Decision Aid Method ESP. In Proceedings of the 7th International Scientific Conference Business and 'Management', Vilnius, Lithuania, 10-11 May 2012; Ginevicius, R., Rutkauskas, A.V., Stankeviciene, J., Eds.; Technika: Vilnius, Lithuania, 2012; pp. 1083-1089.

19. Palevicius, V.; Podviezko, A.; Sivilevicius, H.; Prentkovskis, O. Decision-aiding evaluation of public infrastructure for electric vehicles in cities and resorts of Lithuania. Sustainability 2018, 10, 904. [CrossRef]

20. Stanujkic, D.; Popovic, G.; Zavadskas, E.K.; Karabasevic, D.; Binkyte-Veliene, A. Assessment of Progress towards Achieving Sustainable Development Goals of the "Agenda 2030" by Using the CoCoSo and the Shannon Entropy Methods: The Case of the EU Countries. Sustainability 2020, 12, 5717. [CrossRef]

21. Podviezko, A.; Podvezko, V. Influence of Data Transformation on Multicriteria Evaluation Result. Procedia Eng. 2015, 122, 151-157. [CrossRef]

22. Saaty, T. The Analytical Hierarchy Process; McGraw-Hill: New York, NY, USA, 1980.

23. Saaty, T. Fundamential of The Analytical Hierarchy Process; RWS Publications: Pittsburg, PA, USA, 2000.

24. Kendall, M. Rank Correlation Methods; Griffin: London, UK, 1970; p. 272.

25. Podvezko, V. Determining the level of agreement of expert estimates. Int. J. Manag. Decis. Mak. 2007, 8, 586-600. [CrossRef]

26. Amoozad Mahdiraji, H.; Arzaghi, S.; Stauskis, G.; Zavadskas, E. A Hybrid Fuzzy BWM-COPRAS Method for Analyzing Key Factors of Sustainable Architecture. Sustainability 2018, 10, 1626. [CrossRef]

27. Cereska, A.; Podviezko, A.; Zavadskas, E.K. Assessment of different metal screw joint parameters by using multiple criteria analysis methods. Metals 2018, 8, 318. [CrossRef]

28. Podvezko, V. The Comparative Analysis of MCDA Methods SAW and COPRAS. Eng. Econ. 2011, 22, 134-146. [CrossRef]

29. Amiri, M.; Hashemi-Tabatabaei, M.; Ghahremanloo, M.; Keshavarz-Ghorabaee, M.; Zavadskas, E.K.; Banaitis, A. A new fuzzy BWM approach for evaluating and selecting a sustainable supplier in supply chain management. Int. J. Sustain. Dev. World Ecol. 2020, 1-18. [CrossRef] 
30. Podvezko, V.; Podviezko, A. Use and choice of preference functions for evaluation of characteristics of socio-economical processes. In Proceedings of the 6th International Scientific Conference Business and 'Management', Vilnius, Lithuania, 3-4 May 2010; Ginevicius, R., Rutkauskas, A.V., Pocs, R., Stankeviciene, J., Eds.; Technika: Vilnius, Lithuania, 2010; pp. 1066-1071.

31. Jakimavicius, M.; Burinskiene, M.; Gusaroviene, M.; Podviezko, A. Assessing multiple criteria for rapid bus routes in the public transport system in Vilnius. Public Transp. 2016, 8, 365-385. [CrossRef]

(C) 2020 by the authors. Licensee MDPI, Basel, Switzerland. This article is an open access article distributed under the terms and conditions of the Creative Commons Attribution (CC BY) license (http://creativecommons.org/licenses/by/4.0/). 